Madrygal. Revista de Estudios Gallegos

ISSN: 1138-9664

\title{
Contribución a los estudios de lírica medieval gallegoportuguesa en Argentina en la década de 1960: la obra de Nydia G. B. de Fernández Pereiro ${ }^{1}$
}

\author{
Santiago Disalvo ${ }^{2}$; Carlos Nusch ${ }^{3}$
}

Dedicado a nuestra amiga y maestra, Mercedes Rodríguez Temperley

Recibido: 31 de marzo de 2016 / Aceptado: 18 de outubro de 2018

\begin{abstract}
Resumen. La contribución de muchos argentinos a los estudios medievales ibéricos durante el siglo XX es un hecho ampliamente conocido y documentado. Otro tanto podría decirse de los aportes brasileños y argentinos a las investigaciones específicas sobre lírica gallegoportuguesa. Es necesario, a esta altura del avance de dichos estudios, retomar y revisar estas publicaciones de diversa magnitud y perspectiva, como los escritos académicos de Nydia G. B. de Fernández Pereiro, con el propósito de valorar y considerar su incidencia y su legado. Este artículo se propone como uno de los primeros resultados de la investigación de algunos miembros del proyecto de investigación "Tensiones y contactos en la tradición lírica románica de la Edad Media y el Renacimiento hasta sus proyecciones en la Modernidad" (Dir. G. Chicote y S. Disalvo, 2014-2017), del IdIHCS y la Facultad de Humanidades y Ciencias de la Educación (UNLP, Argentina).
\end{abstract}

Palabras clave: Lírica gallegoportuguesa; lírica trovadoresca; Nydia G. B. de Fernández Pereiro; estudios medievales; Argentina.

\section{[gal] Contribución aos estudos de lírica medieval galegoportuguesa en Arxentina na década de 1960: a obra de Nydia G. B. de Fernández Pereiro}

Resumo. A contribución de moitos arxentinos aos estudos medievais ibéricos durante o século XX é un feito amplamente coñecido e documentado. Outro tanto podería dicirse das aportacións brasileiras e arxentinas ás investigacións específicas sobre a lírica galegoportuguesa. Cómpre, nesta fase do avance destes estudos, retomar e revisar estas publicacións de diversa magnitude e perspectiva, como os escritos académicos de Nydia G. B. de Fernández Pereiro, co obxectivo de valorarmos e considerarmos o seu impacto e legado. Este artigo proponse como un dos primeiros resultados da investigación dalgúns membros do proxecto de investigación "Tensións e contactos na tradición lírica románica da Idade Media e do Renacemento até as súas proxeccións na Modernidade” (Dir. G. Chicote e S. Disalvo, 2014-2017), do IdIHCS e da Facultade de Humanidades e Ciencias da Educación (UNLP, Arxentina).

Palabras chave: Lírica galegoportuguesa; lírica trobadoresca; Nydia G. B. de Fernández Pereiro; estudos medievais; Arxentina.

1 Un primer esbozo de lo que sería este artículo ha sido leído en un panel titulado "La recepción de la lírica gallego-portuguesa medieval en Argentina. Morriña y estudios académicos al otro lado del Océano Atlántico", dirigido por la Dra. Gimena del Rio Riande (IIBICRIT, CONICET - UBA) en el XI Congreso de la Asociación Internacional de Estudos Galegos (6 al 8 de abril de 2015), compartido con ella y Germán Pablo Rossi (UBA). El propósito de esa triple exposición y discusión era señalar algunos hitos en la historia de la recepción de la lírica gallegoportuguesa en el ámbito cultural argentino: la temprana antología de la colección Dorna (Buenos Aires, Emecé, 1941), los estudios académicos de la filóloga Nydia Fernández Pereiro y, por otro lado, los del musicólogo Gerardo Huseby, en la segunda mitad del siglo XX.

2 Universidad Nacional de La Plata, Facultad de Humanidades y Ciencias de la Educación - Instituto de Investigaciones en Humanidades y Ciencias Sociales / CONICET.

Correo-e: santiago.disalvo@gmail.com

3 Universidad Nacional de La Plata, Servicio de Difusión de la Creación Intelectual - Instituto de Investigaciones en Humanidades y Ciencias Sociales - Centro de Servicios en Gestión de Información / CIC.

Correo-e: carlosnusch@prebi.unlp.edu.ar 
[en] Contribution to Studies of Medieval Galician-Portuguese Lyric in Argentina in the 1960s: the Work of Nydia G. B. de Fernández Pereiro

\begin{abstract}
The contribution by many Argentines to the Iberian medieval studies during the 20th century is a widely known and documented fact. The same can be said of the Brazilian and Argentine contributions to the specific research field of Galician-Portuguese lyric. It is necessary, at this point of history, to revisit and review these publications of diverse magnitude and perspective, such as the academic writings of Nydia G. B. de Fernández Pereiro, in order to evaluate and consider its later impact and legacy. This paper comes forth as one of the first results in the investigation by some members of the project "Tensions and contacts in Romanic lyric tradition from the Middle Ages and Renaissance towards its projections in Modernity" (Dir. G. Chicote and S. Disalvo, 2014-2017), in the IdIHCS and the Facultad de Humanidades y Ciencias de las Educación (UNLP, Argentina).
\end{abstract}

Keywords: Galician-Portuguese Lyric; Troubadour lyric; Nydia G. B. de Fernández Pereiro; Medieval Studies; Argentina.

Cómo citar: Disalvo, S. e C. Nusch (2018): "Contribución a los estudios de lírica medieval gallegoportuguesa en Argentina en la década de 1960: la obra de Nydia G. B. de Fernández Pereiro", Madrygal. Revista de Estudios Gallegos 20, pp. 289-297.

El poeta argentino Francisco Luis Bernárdez contribuía en el año 1952, con su Florilegio del Cancionero Vaticano, a la divulgación en la Argentina de la lírica gallegoportuguesa o "portugalaica", como a él le gustaba llamarla, de estos "trovadores, segreres y juglares" de diversas regiones de España y moradores de las cortes de los grandes reyes de León, Portugal y Castilla en los siglos XII y XIII:

de fuera de España llegó a ellas gente del gay saber, formando con sus cantos un río lírico cuyas fuentes estaban en Provenza y en Italia y cuyo caudal desembocó en las cortes ibéricas después de seguir el largo cauce del camino de Santiago y de fertilizar con sus aguas maravillosamente sonoras las tierras que lo bordeaban y sobre todo las que constituían su sagrado objetivo. (Bernárdez 1952: 12)

Más de una década después, el mismo tipo de poesía volvía a recibir el interés del mundo intelectual argentino, esta vez en un ámbito netamente académico, desde una perspectiva crítica, de cuño erudito. En 1968, Nydia G. B. de
Fernández Pereiro publicó su largo artículo "La introducción de la lírica de Provenza en Galicia y Portugal", en el primer número de la revista Romanica. Un estudio sobre el medievalismo argentino, realizado por Mercedes Rodríguez Temperley (2008), señala la Universidad Nacional de La Plata como uno de los centros más importantes donde se desarrollaban investigaciones fundamentales en filología y literatura medieval románica e hispánica durante la primera mitad del siglo XX. En dicho estudio se menciona la producción erudita de Fernández Pereiro. Es el caso que proponemos tratar aquí $\mathrm{y}$, por lo tanto, estas palabras que escribimos bien podrían considerarse una nota suplementaria a tan documentado artículo, publicado por nuestra colega hace diez años.

Nuestra intención es, pues, comentar brevemente algunos de los muchos aspectos posibles que podrían considerarse sobre la obra de Nydia de Fernández Pereiro, intentando de alguna manera iniciar una revisión y discusión de una serie de estudios sobre poesía medieval publicados en la Universidad Nacional de La Plata. Es necesario aclarar que este trabajo en coautoría surge del proyecto "Tensiones y contactos en la tradición lírica románica de la Edad Media y el Renacimiento hasta sus proyecciones en la Modernidad" (dirigido por Gloria Chicote y Santiago Disalvo entre 2014 y 2017), tomando como base una labor previa de análisis y discusión de la principal obra de esta autora, Originalidad y sinceridad en la poesía de amor trovadoresca (1968b).

Este último es el título de la tesis doctoral que Nydia de Fernández Pereiro publicó en el año 1968, bajo la dirección del célebre -y, en ocasiones, cuestionado ${ }^{4}$ - filólogo rumano, Dimitrie Găzdaru, en el Instituto de Filología Románica de la Universidad Nacional de La Plata. Conocido en Argentina con su nombre castellanizado,

[Demetrio] Gazdaru, filólogo y lingüista rumano -a menudo recordado como el maestro de Eugenio Coseriu-, era por los años ' 40 catedrático de Filología Románica en la Universidad de Bucarest y director de la Academia de Rumania en Roma. Gracias a su amistad con el futuro Papa Pablo VI, había podido consultar los archivos secretos del Vaticano de los que obtuvo datos fundamentales para su investigación sobre los aportes de romanidad rumana al mundo eslavo desde la más remota Edad Media. En 1949 
arriba a la Argentina contratado por la UBA para ocupar la cátedra de Filología Hispánica y en 1954 ingresa como profesor en la Universidad Nacional de La Plata, donde desde comienzos de los '60 estará a cargo de las cátedras de Filología Hispánica y de Lingüística, será director del Instituto de Filología desde 1965 (rebautizado a partir de 1969 como Instituto de Filología Románica) y entre 1968 y 1969 auspiciará visitas y conferencias de lingüistas y filólogos de renombre (como Eugene Lozovan, Eugenio Coseriu, Mircea Eliade y Hans Flasche). En julio de 1969, y en el marco del Instituto, inaugura las 'Sesiones filológicas', en las que mensualmente se leían comunicaciones sobre temas filológicolingüísticos que luego eran analizadas por los asistentes. La conferencia inaugural, 'Problemas de estructura sintáctica que presentan las cartas de Hernán Cortés' estuvo a cargo del Prof. Hans Flasche, de la Universidad de Hamburgo. La siguiente exposición, 'Vestigios españoles de bestiarios medievales' estuvo a cargo del mismo Gazdaru, quien un año antes había fundado Romanica -primera revista de lingüística románica del país-donde entre temas diversos, se recogerían trabajos suyos y de reconocidos colaboradores sobre temas de lengua y literatura medieval como, por ejemplo, los de Manuel Alvar, Helmut Hatzfeld y Margherita Morreale. (Rodríguez Temperley 2008: 252-253)

Valga esta contextualización histórica e institucional de la figura de su maestro para comprender acabadamente qué ámbito científico y qué influencias intelectuales propiciaban la investigación y producción erudita de Fernández Pereiro.

No es extraño que su libro sobre la poesía amorosa trovadoresca le valiera a la autora los elogiosos comentarios del gran romanista y medievalista catalán Martín de Riquer, ya que tanto el enfoque dado a la temática de la literatura provenzal como las ideas acerca de su origen y relaciones con la literatura universal resultan tanto innovadoras para su época como sorprendentemente actuales, ya transcurrido exactamente medio siglo desde su publicación.

En este documentado libro, la principal afirmación que Fernández Pereiro señala enfáticamente consiste en el hecho de que no debería juzgarse el amor cortés desde el punto de vista burgués e individualista del amor, así como tampoco creer que los trovadores se hubieran abocado a una tarea de escritura libresca ni, mucho menos, hubieran pretendido tener un público lector. La literatura trovadoresca, tal como se conservó hasta la actualidad, fue algo creado por la tradición cultural que siguió a la desaparición de los trovadores. Así, pues, tal tesis intentaba responder a cierta crítica de la primera mitad del siglo XX, la que reprochaba a los autores provenzales tanto la repetición temática y la monotonía como su falta de originalidad. Para nuestra autora, ese menosprecio crítico surge del grave error de considerar aquella poesía como algo meramente escrito. Fernández Pereiro se adelanta así a las principales investigaciones de los medievalistas más recientes sobre los fenómenos de la oralidad y su complejo vínculo con lo escrito.

La autora afirma, en este sentido, que la percepción del lector, analítica, tiene a mano el objeto en su totalidad para recapitular y manejar la velocidad de lectura de dicha experiencia estética, dado que la composición de este tipo de obra preconiza la concentración. El sujeto oyente, en cambio, es pasivo y no puede alterar la velocidad de sucesión de los elementos del discurso. Esta fugacidad del objeto estético posibilita la repetición como recurso compositivo de manera tal de lograr un mayor rendimiento estético. Las variaciones permiten presentar un objeto sucesivamente desde diferentes aspectos. La percepción del público oyente tiene que ser, por lo tanto, sintética, y llegar al goce estético de manera acumulativa. Llamativamente, años más tarde, el medievalista Paul Zumthor definiría la obra artística medieval en su instancia total, sin reducirla su mera "superficie textual", asimilándola a su performance oral y gestual, es decir, a la formulación estética más completa del acto de transmisión:

La transmisión de boca a oído opera literalmente sobre el texto, lo configura. La performance es precisamente la que convierte una comunicación oral en objeto poético, confiriéndole la identidad social que hace que se la perciba y considere como tal. (Zumthor 1991: 21)

Conscientes de otras muy ricas posibilidades de definición de una obra poética medieval ${ }^{5}$,

5 Si bien no es este el lugar para un análisis pormenorizado sobre esta cuestión, cabe aclarar que la teoría de la mouvance de Paul Zumthor -aparte de sus definiciones más precisas sobre la obra como performance- recibida elogiosamente pero a la que también se le han señalado límites e inadecuaciones, es una las de las visiones posibles junto a otras concepciones que explican también la génesis y el desarrollo de la lírica románica como, por ejemplo, la teoría sociológica de Erich Köhler (1962) y las investigaciones sobre la tradición manuscrita de Avalle (1961). 
simplemente destacamos aquí la relevancia de las afirmaciones de un medievalista de la talla de Zumthor, que definió la naturaleza de la poesía medieval como "preformativa", a fin de llamar la atención sobre la sorprendente coincidencia de visión y concepción en este punto particular, cuatro años antes del Essai de poétique médiévale (1972) y quince antes de La poésie et la voix dans la civilisation médiévale (1984), entre nuestra autora argentina y el célebre medievalista suizo.

Acerca del origen de la poesía provenzal, otras aseveraciones de Fernández Pereiro se revelan, como mínimo, destacables, sobre todo teniendo en cuenta que su publicación es anterior por un año a la de Giuseppe Tavani (1969), quien, de todas maneras, por supuesto, recoge estudios publicados antes del libro de la medievalista argentina. Sin embargo, por más que las voces de otros provenzalistas y romanistas se hayan difundido más exitosamente, la hipótesis de Fernández Pereiro es tanto más apreciable y meritoria cuanto que su obra, surgida de una cierta marginalidad geográfica e institucional con respecto a los estudios de procedencia europea, es temprana, rigurosamente documentada e inserta plenamente en la vertiente de estudios romanistas. Según dicha hipótesis, la poesía provenzal se habría originado en la aristocracia militar y guerrera que evolucionó en la Alta Edad Media y se hizo cada vez más instruida. La épica llegó en Francia a un nivel de refinamiento que la hacía responder al gusto del público más exigente y aristocrático: desarrolló la rima consonante y los versos de medida regular. Una lírica igualmente compleja se desarrollaba, teniendo la épica como modelo, en los castillos de Provenza, para responder a la necesidad de crear una nueva moral social, un sistema de costumbres que reemplazara la vieja moral heroica y caballeresca en tiempos de paz y prosperidad. Esta nueva moral no sería otra que la del amor cortés.

Fernández Pereiro se desempeñó por muchos años como profesora de la cátedra de Literatura Francesa de la Facultad de Humanidades y Ciencias de la Educación de la Universidad Nacional de La Plata, investigando y sacando a luz diversos estudios que han obtenido una desigual atención por parte de los medievalistas más recientes. En el presente marco de discusión, son altamente relevantes las siguientes publicaciones, además del artículo de 1968, "La introducción de la lírica de Provenza en Galicia y Portugal": en primer lugar, el mencionado libro Originalidad y sinceridad en la poesía de amor trovadoresca, publicación del Instituto de Filología (UNLP) también en el año 1968, que ha sido citado en algunas ocasiones como, por ejemplo, en Michel Dubuis (1983: 92 y 112), también por Ana M. Rodado Ruiz (2000: 22), y, antes que ellos, por el prestigioso romanista Martín de Riquer en 1976, además de Carlos Alvar Ezquerra (2014a y 2014b); y, en segundo lugar, el artículo "Uc de Saint Circ et Dom Fernam Garcia Esgaravunha", publicado en 1974, pero presentado antes en un congreso en Francia, en 1967, comunicación que claramente es el antecedente de los estudios que comentaremos aquí. En ese artículo de 1974, la autora corrobora la influencia provenzal directa sobre la formación de la poesía cortesana portuguesa a través del vínculo entre Esgaravunha y el trovador Uc de Saint Circ en la corte de León, influencia no restringida, con toda probabilidad, a este caso particular. Otros provenzales que estaban en la corte de León bien podrían haber entrado en comunicación con poetas gallegos, por más que esas influencias permanezcan hoy en el anonimato. El artículo ha sido citado por Vicenç Beltran (2007) y también por Maria Ana Ramos (2008) en su estudio "Percepção literária e diversidade linguística. A propósito de um refran da lírica galego-portuguesa" en el que se señala el bilingüismo y el multilingüismo como objetos literarios en la composición de la poesía lírica, a propósito del refran de la cantiga A 126 (Cancioneiro da Ajuda), atribuida a Esgaravunha.

Otras publicaciones de la autora, cuyo contenido no expondremos puesto que excedería los límites de nuestras consideraciones sobre la contribución a los estudios gallegos, incluyen el artículo "El antropomorfismo en el Roman de Renart (branche I) y su peculiar forma narrativa", del año 1968, citado en Simpson (1996: 88); una semblanza de su director, "Vida y obra de un maestro: Demetrio Gazdaru", junto con una "Bibliografía de sus publicaciones", en el número 5 de Romanica, del año 1972; el artículo "Le songe d' amour chez les troubadours portugais et provençaux", de 1974; una publicación en actas, "El origen de la tirada del infierno y el paraíso en Aucassin et Nicolette", del año 1986.

En el extenso artículo que más nos interesa rescatar aquí, "La introducción de la lírica de Provenza en Galicia y Portugal", Fernández Pereiro (1968b: 49) pasa revista, primero, a las diferentes posturas vigentes en su época acerca de los orígenes de la lírica gallegoportuguesa, 
detallando sus posibles fases evolutivas antes de la influencia provenzal, que puntualizamos a continuación:

1) "Una lírica tradicional oral, que forma parte constitutiva de la configuración étnica del alma de la población del noroeste de la Península y que es tan antigua como ella";

2) "Una lírica juglaresca popular, nacida en el ámbito más reducido de Galicia, como resultado del movimiento espiritual y de la gravitación ecuménica del santuario de Compostela, que produjo la europeización de esa región de España; puesta en comunicación, gracias a las peregrinaciones, con la poesía popular de otras regiones de la Europa cristiana, viviendo durante más de un siglo en intercambio con ellas, dando y recibiendo motivos o formas, sin perjuicio de desarrollarse de modo propio. Se caracteriza por la aparición de la figura del juglar que compone y canta, autor o colaborador anónimo, que vierte su producción al patrimonio común. A juzgar por lo que sabemos sobre la época de apogeo de las peregrinaciones y por las noticias recibidas de estos profesionales del canto, este período se remonta aproximadamente hasta el siglo XI, época en la cual, del lado árabe de la Península, existía ya una escuela poética culta, que explotaba, en parte, los mismos motivos de canto popular tradicional";

3) "Una lírica juglaresca cortesana que evoluciona rápidamente hacia un arte trovadoresco, a causa del interés mostrado a principio del siglo XII por reyes y señores en tener en sus castillos y palacios equipos de juglares bajo su protección y de la participación cada vez mayor de los mismos señores en esas actividades".

Mediante un documentado estado de la cuestión hasta su momento, la autora pasa a rastrear el problema de la influencia provenzal, retomando y discutiendo los estudios de Carolina Michaëlis, Alfred Jeanroy, Henry R. Lang y Ramón Menéndez Pidal, para focalizarse después en el análisis de un caso específico.

La cronología de las distintas visitas de los provenzales a la región no da cuenta cabal de las razones de una influencia que, según la autora, sólo "es potente desde fines del siglo XII hasta fines del siglo XIII" (Ibid. 52), es decir, con una segunda generación de poetas provenzales. A la cuestión de por qué en Galicia y Portugal no se produce, dada esta inmigración occitana, una poesía en provenzal, intentará responder de una forma que se aparta de las teorías elaboradas hasta entonces: "si hubo un proceso de refinamiento para cantar en lengua nacional, es que el objetivo era muy otro que el de imitar el canto de los provenzales" (Id.). Y continúa:

Se ve, pues, que el problema de la datación de la influencia provenzal es en el fondo algo más que un problema cronológico, pues lo que se trata de decidir en él es, en última instancia, si esa escuela de poesía culta, que todos reconocen [que] existía ya a fines del siglo XII, era de orientación nacional o estaba ya bajo el influjo de Provenza. Para sostener lo primero, nos basamos, ante todo, según ya hemos insinuado, en que la existencia de una lírica culta preprovenzalizante es la única condición de posibilidad del uso del idioma vernáculo en la poesía galaico-portuguesa del siglo XIII. Basta esta consideración: Cuando los poetas castellanos y de otras regiones de la península son influidos por la lírica gallega, no escriben sus obras en castellano, sino en gallego. La causa es: no había una lírica castellana culta preexistente, no obstante haber una lírica castellana de tradición oral, como Menéndez Pidal repetidamente ha mostrado. Exactamente igual es la relación entre Provenza y Cataluña y entre Provenza y el norte de Italia, países que adoptaron el idioma de la literatura influyente, porque no tenían una literatura culta propia [en esto la autora sigue a Jeanroy, La poésie lyrique des troubadours, 1934], al contrario de lo que ocurrió en el norte de Francia, en Alemania y en el noroeste de la Península, donde Provenza no impuso su idioma a la poesía, porque ya existía en esas regiones una lírica autóctona, que había salido del estado meramente popular. (Ibid. 53-54)

Así, pues, nuestra autora señala el Reino de León como uno de los focos de influencia provenzal más importantes de la Península, sobre todo bajo el reinado de Alfonso IX. Las nuevas tendencias provenzalizantes se habrían dado a partir de una segunda o tercera generación de poetas cultos autóctonos, momento puntual que la autora identifica con una "coyuntura concreta" en la que se produce esta transformación o viraje de la poesía culta primitiva de la región hacia modelos de virtuosismo métrico e ideales amorosos propiamente occitanos: "esa coyuntura se dio, a nuestro juicio, cuando el acceso al trono de Portugal de Alfonso II, sucesor de Sancho I, en el año 1211, provocó el exilio de los infantes don Pedro y don Fernando, junto con los adictos de éstos, los de Sousa, la familia de más alta alcurnia de Portugal" (Ibid. 56). Aquí se encuentran también Abril Peres de Lumiares y otros, todos los cuales se refugiaron en León, en la corte de Alfonso IX. A la familia de Sousa pertenecía don Fernan García, apodado Esgaravunha, trovador de Portugal cuya actividad literaria se registra en la segunda mitad del siglo XIII, y que "[m]embro da poderosa familia 
dos Sousa, era fillo de Garcia Mendiz de Eixo e marido da filla de Abril Perez. Foi autor de 20 textos: 18 cantigas de amor, 1 cantiga de escarnio e 1 sátira literaria" (López y Ferreira 2011) ${ }^{6}$.

El estudio pormenorizado que realiza la autora la lleva a concluir que, indudablemente, este trovador había tenido contacto con el trovador provenzal Uc de Saint Circ:

es en verdad sorprendente la identidad general de estructura que presentan las series de canciones de amor compuestas por ambos poetas, 18 en total las de Esgaravunha, 15 las de su modelo provenzal. (Fernández Pereiro 1968b: 56)

Es Esgaravunha el poeta más representativo y el único portugués cuya obra proviene directamente de las fuentes provenzales (...) Fue él quien ha forjado de entrada la forma tipo de canción galaico-portuguesa provenzalizante (Ibid. 68)

Ahora bien, existe una cuestión que es de sumo interés, en la que ha de indagarse con el fin de lograr ulteriores avances en la investigación de la lírica románica. Aunque la autora aclarara bien, ya desde el título del artículo, que trataría sobre la lírica provenzal introducida "en Galicia y Portugal", es inevitable preguntarse por este fenómeno en todo el corpus lírico gallegoportugués, aunque no pertenezca geográficamente al territorio indicado. Más específicamente, nos obligaría a volver sobre la cuestión de la presencia de los modelos occitanos en la poesía ibérica medieval, y en qué grado se llegó a dar, por ejemplo, en obras como las Cantigas de Santa María de Alfonso X, tan peculiares en su inscripción dentro del corpus poético gallegoportugués ${ }^{7}$. La cuestión, claro está, no es nueva en absoluto, pero una renovada profundización en los viejos hallazgos de Fernández Pereiro podría todavía echar luz sobre esta cuestión: aquello de que "el objetivo era muy otro que el de imitar el canto de los provenzales" (Ibid. 52) debería ponerse a prueba nuevamente en las cantigas alfonsíes. Tales interrogaciones, sobre todo en este caso, nos llevan necesariamente a considerar un segundo aspecto, obviamente no incluido en los estudios de la autora, a saber: el de la influencia de la música occitana y transpirenaica, como posteriormente lo estudiaría el musicólogo argentino Gerardo Huseby en el ámbito académico nacional e internacional (1983, 1987, 1999), entre otros ${ }^{8}$.

Sin dejar de tener en cuenta la influencia específicamente cortesana, un nuevo análisis de las posibles fuentes de las Cantigas de Santa María debe contemplar necesariamente la presencia muy próxima de las formas líricas de la liturgia. En este sentido, sigue siendo válida aquella afirmación de la misma autora en la que, retomando otras investigaciones, considera tal filiación en la poesía trovadoresca provenzal, que podría aplicarse a la creación poética gallegoportuguesa, muy especialmente la alfonsí:

hay un sector de la cultura latina medieval que no pudo ser extraño a los trovadores. Nos referimos a la poesía del oficio religioso, género no limitado a los eruditos, que no existía meramente como literatura escrita, sino que lo cantaban habitualmente los fieles de todas las clases sociales. (...) Spanke puso de relieve la poesía paralitúrgica como la verdaderamente influyente; tratábase de cantos que no pertenecían al oficio religioso propiamente dicho, pero que se cantaban en las iglesias por imposición del gusto popular, de temática incluso profana: los tropos, de los cuales el versus o conductus habría influido en las composiciones de Guillermo IX. (Fernández Pereiro 1968a: 167-168) ${ }^{9}$

6 Baste aquí la noticia que se puede leer de él en la página web del Projeto Littera de Lisboa: http://cantigas.fcsh.unl.pt (Lopes y Ferreira 2011). Para tener una visión más completa de este trovador, es necesario remitirse también a la información ofrecida en el Dicionário da Literatura Galego-Portuguesa Medieval, coordinado por Giulia Lanciani y Giuseppe Tavani (1993). Cf. también Brea 1996, así como la Base de datos MedDB del Centro Ramón Piñeiro de Santiago de Compostela (http://www.cirp.gal/meddb).

7 Valga a modo de referencia sintética que cita, a su vez, a referentes más autorizados sobre la influencia provenzal en poesía y música en la obra alfonsí, nuestro artículo sobre los esponsales y la drudaria en las Cantigas de Santa María (Disalvo 2007: 162, 164 y ss.).

8 A los estudios pioneros de Anglès (1943-1964) es necesario agregar la referencia de muchos otros, especialmente los más recientes de Manuel Pedro Ferreira (1993, 1999-2000, 2009).

9 Aunque no es posible abordar una cuestión tan compleja aquí, la terminología "paraliturgia" / "paralitúrgico" es puesta en discusión hoy en día, ya que todas estas composiciones surgieron como desarrollos "ornamentales" o "comentarios poéticos", interpolados en los textos litúrgicos, formando así, pues, parte de la liturgia. Para un completo estudio sobre el florecimiento de estas formas en el siglo XII, puede consultarse la obra de Margot Fassler, Gothic Song: "this was a time during which several repertories of liturgical texts and music either died out or were truncated and modified, and several new kinds of texts and music -rhymed offices, late sequences, versus and conductus, and some styles of polyphonic music- first flourished" (1993: 9). 
Hay aquí, ciertamente, un punto de unión y contraste que enlaza la lírica gallegoportuguesa, el mundo trovadoresco occitano y la poesía litúrgica.

En fin, habiendo pasado más de cuatro décadas, es necesario volver sobre los estudios de Nydia de Fernández Pereiro, seguramente para completar, corregir o discutir muchas cuestiones... En nuestro caso, al menos, seguramente para aprender, y mucho, de sus investigaciones y de un esfuerzo de erudición, realizado en una época desprovista de los medios técnicos actuales de recopilación y procesamiento de información, con una documentación copiosa $y$ en una universidad argentina, lugar lejano de las fuentes manuscritas que, por otra parte, la autora parece conocer bien.

De manera inevitable, se abren más cuestiones al llegar a las conclusiones, necesariamente provisionales. En primer lugar, es una lírica letrada primitiva y "no tradicional" (en sentido pidaliano) la que parece ser el foco de interés de la autora, en un contexto académico que, no pocas veces, declaraba estar interesado en focalizarse precisamente sobre lo tradicional-popular más que sobre otra cosa:

La primitiva lírica gallega culta era un movimiento nuevo, del cual los poetas de entonces eran originales creadores. Una escuela poética en esas circunstancias difícilmente recibe influencia de otra. El propio creador valora mucho su obra y se identifica con ella; abandonarla significaría matarse a sí mismo. Pero ya no ocurre lo mismo con sus descendientes, que la reciben hecha. Es propio de los herederos de una tradición culta una actitud crítica ante lo que reciben, porque toda nueva generación tiene tendencia a la creación y a la originalidad. (Fernández Pereiro 1968b: 55)

A este respecto, la cuestión de la "sinceridad" poética, aunque la autora la haya aplicado más explícitamente al mundo occitano que a otro sector de la poesía románica, es de capital interés. Al discutir acerca de la poesía trovadoresca -si se trata de meras disertaciones abstractas sobre el amor o bien de un reflejo cierto de los amoríos carnales de los poetas- el mismo Martín de Riquer, en 1975, exhortando a "evitar emitir juicios de conjunto que afectan nada menos que a unos trescientos cincuenta poetas que produjeron a lo largo de dos siglos", aclara que:

Incide ello en el grave problema de la sinceridad de los trovadores, tan bien estudiado en el libro de Nydia G. B. de Fernández Pereiro, la cual, con acierto, analiza la importancia de aquellas palabras que se encuentran en la Vida de Uc de Sant Circ: ... mas non fez gaires de las cansos, quar anc non fo fort enamoratz de neguna; mas ben se saup feingner enamoratz ad ellas ab son bel parlar. E saup ben dire en las soas cansos tot so que'ill avenia de lor, e ben las saup levar $e$ ben far cazer. Mas pois qu'el ac moiller non fetz cansos. (Riquer 2012: 92) ${ }^{10}$

La cuestión de la sinceridad poética, ligada al concepto de originalidad, cuestiones de las que trata in extenso en su tesis sobre los trovadores provenzales, no es algo de importancia menor como problemática planteada, aunque pueda ser degradada (en especial en gran parte de nuestros ámbitos académicos) a la categoría de "prejuicio romántico". De este prejuicio acaso pudo haber participado la autora o, por el contrario, haber intentado rebatirlo con poco éxito, lo cual deja intacto el interés sobre la cuestión, que puede detectarse vivo en muchas aproximaciones a la lírica, desde las indagaciones estéticas de T. S. Eliot hasta las más recientes y rigurosamente académicas de Peter Dronke (1970) en su Poetic Individuality.

Por último, asistimos con el estudio de Fernández Pereiro a una puesta en práctica de una perspectiva que es, a todas luces, romanista más que hispanista, lo cual es innovador para los estudios medievales argentinos de su época. El centrarse en el romanismo más que en el hispanismo está, a nuestro juicio, en estrecho vínculo con su labor bajo la dirección de un investigador cuyos acercamientos a la poesía medieval, incluso la hispánica, provienen de su mirada "panrománica" con raíces profundas en la latinidad y lo "románico oriental":

el Dr. Gazdaru investigó durante más de veinte años, en las grandes bibliotecas europeas, la suerte de un tema literario incorporado en el romance viejo español Fontefrida. Un capítulo de tales estudios apareció en 1954 con el título Antecedentes latinos del tema literario de Fontefrida ( $\left.\mathrm{N}^{\mathrm{o}} 190\right)$. Otro más extenso dedicó en 1962 a los Factores orientales, griegos y

10 Carlos Alvar (2014a: 144) retomará esta cuestión en términos muy similares, con la referencia explícita a la obra de Fernández Pereiro, al considerar las concepciones del amor y la expresión de la sinceridad de los sentimientos en la poesía del siglo XIII. 
egipcios en la elaboración del tema literario de Fontefrida ( $\left.\mathrm{N}^{\mathrm{o}} 309\right)$ (...) [y a otros, con] el método de la geografía folklórica, que había aplicado, en escala reducida, en la difusión de este tema en las literaturas románicas ya en 1935 ( $\mathrm{N}^{\circ}$ 55). (Fernández Pereiro 1972: 12) ${ }^{11}$

Los estudios medievales gallegoportugueses, en especial en lo que se refiere a la poesía lírica de tipo trovadoresco, se han visto enriquecidos enormemente por las indagaciones profundas de esta investigadora argentina, en parte olvidada por sus mismos compatriotas. Mucho podría seguir diciéndose acerca de sus agudas y delicadas observaciones y reflexiones, acaso discutibles, sobre todo desde el pretendido afán de objetividad y la estrecha mirada de cierto pretendido "rigor científico" de nuestros días, pero ciertamente provocativas y favorecedoras de nuevas preguntas, que son las mismas viejas preguntas que quedan sin ser respondidas del todo. La vigencia y actualidad de esta autora en el contexto de los estudios medievales y románicos del siglo XXI merece una revisión mucho más honda y genuinamente crítica de su obra, que es lo que esperamos haber aportado, de manera incipiente y discreta, con estas páginas.

\section{Referencias bibliográficas $^{12}$}

Alvar Ezquerra, Carlos (2014a): "Li occhi in prima generan l'amore: consideraciones sobre el concepto de 'amor' en el siglo XIII”, en J. Ll. Martos (coord.), De poesía medieval con sus glosas agora nuevamente añadidas. Alacant: Universitat d'Alacant, pp. 143-160.

— (2014b): "Carolina Michaëlis y la lírica tradicional”, en J. L1. Martos (coord.), De poesía medieval con sus glosas agora nuevamente añadidas. Alacant: Universitat d'Alacant, pp. 359-378.

Anglès, Higini (1943-1964): La música de las cantigas de Santa María del Rey Alfonso el Sabio (facsímil, transcripción y estudio crítico). Barcelona: Diputación Provincial, Biblioteca Central, 4 vols.

Avalle, D'Arco Silvio (1961): La letteratura medievale in lingua d'oc nella sua tradizione manoscritta; problemi di critica testuale; reed. L. Leonardi (1993): I manoscritti della letteratura in lingua d'oc, Torino: Einaudi.

Base de datos da Lírica Profana Galego-Portuguesa (MedDB) [base de datos en liña]. Versión 3.4. Santiago de Compostela: Centro Ramón Piñeiro para a Investigación en Humanidades (http://www.cirp.gal/meddb).

Beltran, Vicenç (2007): Poética, poesía y sociedad en la lírica medieval (Verba: Anuario Galego de Filoloxía, anexo 59). Santiago de Compostela: Universidade de Santiago de Compostela, Servizo de Publicacións e Intercambio Científico.

Bentivegna, Diego (2015): "Benvenuto Terracini y Demetrio Gazdaru: Dos lecturas desplazadas del archivo glotológico de Graziadio Isaia Ascoli”, Orbis Tertius 20/22, pp. 21-31 (http://www.memoria.fahce. unlp.edu.ar/art_revistas/pr.7092/pr.7092.pdf).

Bernárdez, Francisco L. (1952): Florilegio del Cancionero Vaticano (Poesía amorosa galaicoportuguesa de la Edad Media). Buenos Aires: Losada.

Brea, Mercedes (coord.) (1996): Lírica galego-portuguesa. Corpus completo das cantigas medievais, con estudio biográfico, análise retórica e bibliografía específica. Santiago de Compostela: Centro de Investigacións Lingüísticas e Literarias "Ramón Piñeiro", 2 vols.

Disalvo, Santiago (2007): "Esponsales, drudaria y amor virginal en las Cantigas de Santa María", Revista do Centro de Estudos Portugueses 27/37, pp. 161-178.

Dronke, Peter (1970): Poetic Individuality in the Middle Ages: New Departures in Poetry 1000-1150. Oxford: Clarendon.

Dubuis, Michel (1983): "Estudio de una canción y una esparza de Jorge Manrique", Cahiers du CRIAR (Centre de recherches ibériques et ibéro-américaines de l'université de Rouen) 1, pp. 91-112.

Fassler, Margot (1993): Gothic Song. Victorine Sequences and Augustinian Reform in Twelfth-Century Paris. Cambridge: University Press (Cambridge Studies in Medieval and Renaissance Music).

11 Se refiere la autora a una serie de trabajos de su maestro que, con casi treinta años de distancia, ilustran los intereses literarios del filólogo rumano abierto siempre a tales horizontes panrománicos y orientales: Originea şi răspândirea motivului "amărîtă turturică " în literaturile romanice (Iaşi 1934), traducido como Das Motiv der betrübten Turteltaube ["la tórtola triste"] in der romanischen Literatur y "Factores orientales, griegos y egipcios en la elaboración del tema literario de 'Fonte Frida"' (Gazdaru 1961).

12 Dadas las características de este artículo, se incluye aquí tanto la bibliografía utilizada y citada como la referenciada de la autora en cuestión o de quienes la citan. 
Fernández Pereiro, Nydia G. B. de (1968a): Originalidad y sinceridad en la poesía de amor trovadoresca. La Plata: Universidad Nacional de La Plata, Instituto de Filología.

(1968b): "La introducción de la lírica de Provenza en Galicia y Portugal”, Romanica 1 (Instituto de Filología - UNLP), pp. 19-68.

(1968c): "El antropomorfismo en el Roman de Renart (branche I) y su peculiar forma narrativa", en A. Quilis, R. B. Carril y M. Cantarero (eds.), Actas del XI Congreso Internacional de Lingüística y Filología Románicas, vol. 2, pp. 737-746.

(1972): "Vida y obra de un maestro: D. Gazdaru", Romanica 5, pp. 5-16.

(1974a): "Uc de Saint Circ et Dom Fernam Garcia Esgaravunha", en G. Moignet y R. Lassalle (eds.), Actes du 5ème. Congrès International de Langue \& Littérature d'Oc et d'Etudes Franco-Provençales (Nice, 6-12 Septembre, 1967). Paris-Nice: Les Belles Lettres (Publications de la Faculte des Lettres et des Sciences Humaines de Nice, 13), pp. 130-165.

(1974b): "Le songe d'amour chez les troubadours portugais et provençaux", en J. Caluwé, J. M. D’Heur y R. Dumas (eds.), Mélanges d'histoire littéraire, de linguistique et de philologie romanes offerts à Charles Rostaing (Directeur de l'Institut d'Études provençales de la Sorbonne) par ses collèges, ses élèves et ses amis. Liège: Association des Romanistes de l'Université de Liège, pp. 301-315.

Ferreira, Manuel Pedro (1993): “A música das cantigas galego-portuguesas: balanço de duas décadas de investigação (1977-1997)”, en M. Brea (ed.), Actas do congreso “O mar das Cantigas”. Santiago de Compostela: Xunta de Galicia, pp. 235-250.

(1999-2000): "The Influence of Chant on the Cantigas de Santa Maria", Bulletin of the Cantigueiros de Santa Maria 11-12, pp. 29-40 (también publicado en Publicações CESEM, Universidade Nova de Lisboa, 1999: http://www.fcsh.unl.pt/29_10_02/revistas/mpf_chant99.htm).

(2009): Aspectos da Música Medieval no Ocidente Peninsular. Volume I. Música Palaciana (Estudos Musicológicos, 33). Lisboa: Fundação Calouste Gulbenkian.

Gazdaru, Demetrio (1962): "Factores orientales, griegos y egipcios en la elaboración del tema literario de 'Fonte frida'”, Humanidades (FaHCE-UNLP) 38, pp. 139-168.

Huseby, Gerardo (1983): “The Medieval Modal System”, en The 'Cantigas de Santa Maria'and the Medieval Theory of Mode, Stanford: Stanford University.

(1987): “The Common Melodic Background of 'Ondas do mar de Vigo' and Cantiga 73”, en I. J. Katz y J. E. Keller (eds.), Studies on the 'Cantigas de Santa Maria': Art, Poetry and Music. Madison: Hispanic Seminary of Medieval Studies.

_ (1999): "El parámetro melódico en las Cantigas de Santa María: Sistemas, estructuras, fórmulas y técnicas compositivas”, en J. Montoya y A. Domínguez Rodríguez (eds.), El Scriptorium alfonsí: de los Libros de Astrología a las "Cantigas de Santa Maria". Madrid: Universidad Complutense de Madrid.

Köhler, Erich (1962): Trobadorlyrik und höfischer Roman. Aufsätze zur französischen und provenzalischen Literatur des Mittelalters (Neue Beiträge zur Literaturwissenschaft, 15). Berlin: Rütten \& Loening.

Lanciani, Giulia y Giuseppe Tavani (coord.) (1993): Dicionário da Literatura Galego-Portuguesa Medieval. Lisboa: Caminho.

Lopes, Graça Videira y Manuel Pedro Ferreira et al. (2011): Cantigas Medievais Galego Portuguesas [base de dados online]. Projeto Littera. Lisboa: Instituto de Estudos Medievais, FCSH/ NOVA (http:// cantigas.fcsh.unl.pt).

Ramos, Maria Ana (2008): "Percepção literária e diversidade linguística. A propósito de um refran da lírica galego-portuguesa”, en H.-J. Döhla, R. Montero-Muñoz y F. Báez de Aguilar González (eds.), Diálogo: el iberorromance y su diversidad lingüistica y literaria. Ensayos en homenaje a Georg Bossong. Madrid: Iberoamericana/Vervuert, pp. 489-508.

Riquer, Martín de (2012 [1975]): Los trovadores. Historia literaria y textos. Barcelona: Ariel.

Rodado Ruiz, Ana María (2000): "Tristura conmigo va": fundamentos de amor cortés, Cuenca: Universidad de Castilla-La Mancha.

Rodríguez Temperley, María Mercedes (2008): "La Edad Media en las tierras del Plata (a propósito del medievalismo en la Argentina)", Revista de poética medieval 21, pp. 221-293.

Simpson, James (1996): Animal Body, Literary Corpus: The Old French Roman de Renart. Amsterdam: Rodopi.

Tavani, Giuseppe (1969): Poesia del Duecento nella Penisola Iberica. Problemi della galego-portoghese. Roma: Edizioni dell'Ateneo.

Zumthor, Paul (1991): "La poesía y la voz en la civilización medieval”, en A. Deyermond (ed.), Historia y crítica de la literatura española. 1/1 Edad Media. Primer suplemento. Barcelona: Crítica. 